\title{
Combustion Chemistry of Alcohols:
}

\section{Experimental and Modeled Structure of a Premixed 2-Methylbutanol Flame}

\author{
A. Lucassen ${ }^{1 *}$, S. Park ${ }^{2}$, N. Hansen ${ }^{1}$, S.M. Sarathy ${ }^{2}$ \\ ${ }^{1}$ Sandia National Laboratories, 7011 East Avenue, Livermore, CA, 94550, USA \\ ${ }^{2}$ King Abdullah University of Science and Technology, Thuwal 23955-6900, Kingdom of Saudi \\ Arabia
}

Corresponding authors' contact details:

A. Lucassen

Sandia National Laboratories

7011 East Avenue MS 9055

Livermore, CA, 94550, USA

Email: arnas.lucassen@gmail.com

Phone: +1-925-294-3344

\section{Colloquium:}

Laminar Flame

Word Count(by Microsoft word):

Abstract:

159

Introduction:

353

Chemical Kinetic Model:

252

Experimental Methods:

374

Results and Discussion:

1390

Conclusion:

179

Acknowledgements:

116

31 References:

577

8 Figures: $185+375+417+166+333+278+250+5412545$

Total:

5786

Supplementary Material: Supplementary material is available

Color figures in online version only. 


\title{
Combustion Chemistry of Alcohols:
}

\section{Experimental and Modeled Structure of a Premixed 2-Methylbutanol Flame}

\author{
A. Lucassen ${ }^{1}$, S. Park ${ }^{2}$, N. Hansen ${ }^{1}$, S.M. Sarathy ${ }^{2}$ \\ ${ }^{1}$ Sandia National Laboratories, 7011 East Avenue, Livermore, CA, 94550, USA \\ ${ }^{2}$ King Abdullah University of Science and Technology, Thuwal 23955-6900, Kingdom of Saudi \\ Arabia
}

\begin{abstract}
:
This paper presents a detailed investigation of 2-methylbutanol combustion chemistry in lowpressure premixed flames. This compound is particularly interesting because it is a lignocellulosicbased, next-generation biofuel. The detailed chemical structure of a stoichiometric low-pressure (25 Torr) flame was determined using flame-sampling molecular-beam mass spectrometry. A total of 55 species were identified and subsequently quantitative mole fraction profiles as function of distance from the burner surface were determined. In an independent effort, a detailed flame chemistry model for 2-methylbutanol was assembled based on recent knowledge gained from combustion chemistry studies for butanol isomers [Sarathy et al Combust. Flame 159 (6) (2012) 2028-2055] and isopentanol (3-methylbutanol) [Sarathy et al Combust. Flame 160 (12) (2013) 2712-2728]. Experimentally determined and predicted mole fraction profiles were compared to demonstrate the model's predictive capabilities, and to suggest areas where improvement is needed. Examples of individual mole fraction profiles are discussed together with the most significant fuel consumption pathways to highlight the combustion chemistry of 2-methylbutanol.
\end{abstract}

Keywords: alcohol combustion; 2-methylbutanol; biofuels; mass spectrometry; kinetic modeling 


\section{Introduction}

The use of bio-derived fuels has the potential to reduce fossil fuel consumption and prevent climate forcing by minimizing carbon dioxide emissions into the atmosphere. Besides the energy (in)dependence and carbon neutrality, many other aspects have to be taken into account when considering biofuel utilization, e.g. land and water use in competition to food production and pollution prevention. For the next-generation bio-derived fuels, conversion of lignocellulosic biomass via biotechnological routes is of special interest $[1,2]$ and many different fuels have been produced in small scales [3].

These new classes of fuels contain chemical structures not present in fossil fuels, thus giving rise to different combustion chemistry that needs to be studied with the same level of detail as done for the hydrocarbon fuels [4]. 2-methylbutanol is a proposed biofuel that can be produced from various substrates by modified E. coli bacteria [5] and photosynthetic from $\mathrm{CO}_{2}$ by cyanobacteria [6], so a detailed study of its combustion chemistry is warranted. In this paper we describe a detailed experimental and modeling study of the high-temperature combustion chemistry of 2-methylbutanol in a premixed flame.

Over the last few years, extensive investigations and modelling efforts for the alcohol and especially butanol combustion chemistry [7-12] have made truly predictive models for larger model fuels possible. With the longer chain alcohols being better suited for the use in internal combustion engines than the butanols, the focus of alcohol combustion chemistry research is shifting now to the $\mathrm{C}_{5}$ alcohol family including $n$-pentanol [13-15], iso-pentanol (3-methylbutanol) [16-18], and 2methylbutanol $[14,19]$.

The two existing studies on 2-methylbutanol combustion include flame speed and shock tube ignition delay measurements $[14,19]$, but no detailed investigation on its combustion chemistry exists. To close this gap, we present herein the experimental and modeled chemical structures of a premixed flame of 2-methylbutanol. An experimental dataset is generated and used to test the predictive behavior of an independently assembled chemical kinetic model. It will be discussed that 
with the knowledge gained from the work on the butanol isomers [11] and iso-pentanol [17], a predictive model with good predictive capabilities can be generated also for the 2-methylbutanol.

\section{Chemical Kinetic Model}

The detailed chemical kinetic model for 2-methylbutanol is based on previous modeling studies of the $\mathrm{C}_{4}$-alcohols [11] and iso-pentanol [17] and a similar methodology was used to develop a high-temperature chemistry model for 2-methylbutanol. For this work, the iso-pentanol model [17] has been extended by adding 24 species and 201 reactions to represent the high-temperature combustion chemistry of 2-methylbutanol and various intermediate species. The reaction classes and rates follow directly from previous work, as described in Ref. [11]. With regards to the unimolecular decomposition reactions of the fuel, the recently updated reaction rate coefficients from Refs. [20, 21] on the thermal decompositions of $\mathrm{C}_{4}$-alcohols were adopted in this study to improve predictions by the present model. Thermodynamic data were calculated using the THERM program of Ritter and Bozzelli [22]. The correlations developed by Tee et al. [23] were used for transport properties to calculate the Lennard-Jones (LJ) collision diameter and potential well depth. The model's predictions have been favorably compared with the flame speed data from Ref. [19] (shown in Fig. 1) and the high-temperature ignition delay data from Ref. [24] (shown in Fig. 2) with very good agreements.

The present kinetic model is provided in the Supplementary Material. The simulation for the low-pressure premixed flame was performed with the PREMIX module in CHEMKIN PRO [25] using the experimental temperature profile as input parameter. The simulations accounted for thermal diffusion (i.e., Soret effect), assumed mixture- averaged transport, and the solutions were highly resolved with approximately 200 grid points (GRAD 0.1, CURV 0.1). 


\section{Experimental Methods}

A laminar premixed flame of 2-methylbutanol was stabilized on a 60-mm stainless steel flatflame burner. The stoichiometric flame had a total flow of four standard liters per minute (slm) and was diluted by 50\% argon. The flame was kept at a pressure of 25 Torr. Gas flows were controlled by calibrated mass flow controllers and the stream of the liquid fuel was metered by a syringe pump. All flows are estimated to be within $\pm 5 \%$ of the target value.

The flame temperature was measured using $\mathrm{OH}$ laser induced fluorescence as described in Ref. [10]. Subsequently, the data were corrected for the probe perturbation as described in Ref. [26] and used as input parameters for the model calculations.

The chemical structure of the flame was analyzed by a flame-sampling molecular-beam sampling setup coupled to a mass spectrometer (MBMS). Single-photon ionization by synchrotrongenerated vacuum-UV radiation with an energy-resolution of $E / \Delta E \sim 0.04 \mathrm{eV}$ was combined with a custom-built reflectron time-of-flight spectrometer. The principle setup and basic procedures are described in Refs. [27]. The mass spectrometer therein was updated with an orthogonal TOF [28] manufactured by Kaesdorf. This new mass spectrometer is capable of providing high mass resolution $(m / \Delta m \sim 3000)$ at continuous ionization. This new experimental capability allows for separation of most hydrocarbons from single and double oxygenated species. More than 50 flame species could be identified based on their mass-to-charge ratios and photoionization efficiency curves. For these species, mole fraction profiles as function of distance from the burner were generated as described in Ref. [29]. The full set of data is presented in the Supplementary Material and only a few mole fraction profiles are discussed herein in detail.

When comparing the experimental data to model predictions, one must be mindful of the experimental uncertainties. As described in similar studies [8, 30], the mole fractions can vary by $\pm 20 \%$ for the main species and by up to a factor of four for species with estimated cross sections. With regards to the probe position, the estimated accuracy is within $\pm 0.5 \mathrm{~mm}$. The accuracy of the flame temperature measurements is expected to be $\pm 150 \mathrm{~K}$ in the post flame zone, but somewhat 
larger in the preheat zone, where $\mathrm{OH}$ concentrations are very small and large temperature gradients exist.

\section{Results and Discussion}

In general, the modeling results agree within the expected uncertainties with the experimental results as shown in Fig. 3, which contains the comparison for the major product species $\left(\mathrm{H}_{2}, \mathrm{H}_{2} \mathrm{O}\right.$, $\mathrm{CO}, \mathrm{O}_{2}, \mathrm{Ar}, \mathrm{CO}_{2}$, fuel). Again, all modeling results shown in this paper are truly predictive, as the experiment was performed and analyzed independently from the model development. Also, no profiles were shifted to achieve a good comparison and no changes were made to the rate coefficients in the model to improve agreement.

With regards to the fuel consumption, similar work on the combustion chemistry of butanol isomers has shown that, depending to some extent on the flame conditions, the fuel is consumed through $\mathrm{H}$-abstraction reactions and/or unimolecular dissociation [10, 31]. The primary fuel consumption pathways of 2-methylbutanol are shown in Fig. 4 based on H-abstraction by flame radicals (mainly $\mathrm{H}, \mathrm{O}$, and $\mathrm{OH}$ ) followed by $\beta$-scission combined with the observed species. The molecule has no symmetry, so there are 6 different possible positions for $\mathrm{H}$-abstractions with different statistical probability. According to such a consumption scheme, the H-abstraction from the hydroxyl moiety, which is the least favorable, can lead to 2-methylbutanal $\mathbf{7}$ or but-2-yl $\mathbf{1 7}$ and formaldehyde. The resonance-stabilized radical at the $\alpha$-position can lead to 2-methylbutanal 7 as well. Additionally, 2-methylbut-1-en-1-ol 8 and methyl plus but-1-en-1-ol 12 can be produced, as well as prop-1-en-1-ol 18 plus $\mathrm{C}_{2} \mathrm{H}_{5}$. The abstraction of the sole $\beta$-H-atom leads to 2-methylbut-1-en1-ol 8, 2-methylidenebutan-1-ol 9, 2-methylbut-2-en-1-ol 10, 2-methylbut-1-ene $\mathbf{1 3}$ plus $\mathrm{OH}$ and 2methylprop-2-en-1-ol 14 plus methyl. The abstraction of primary $\mathrm{H}$ atoms on the methyl group can lead to 2-methylidenebutan-1-ol 9, 1-butene 19 plus formyl, and prop-2-en-1-ol 20 plus $\mathrm{C}_{2} \mathrm{H}_{5}$. Abstraction on the $\gamma$-C atom can produce 2-methylbut-2-en-1-ol 10 again, but-2-en-1-ol 15 plus methyl, 2-butene 21 plus formyl and 2-methylbut-3-en-1-ol 11. Finally, abstraction at the primary $\delta$ C-atom yields 2-methylbut-3-en-1-ol 11 or propanol-2-yl 16 plus ethylene. 
Selected mole fraction profiles are described in the following paragraphs and the full set of data can be found in the Supplementary Material.

The branching ratio for the abstraction reaction is according to the model at $1200 \mathrm{~K}$, which equals an distance from the burner surface of $2 \mathrm{~mm}$, as follows: $32 \%$ reacts to $2,12 \%$ to $3,23 \%$ to 4 15\% each of $\mathbf{5}$ and $\mathbf{6}$ and only 1.3\% reacts to $\mathbf{1}$. Unimolecular decomposition is negligible with a total of below $1 \%$ at this position in the flame. The H-abstraction branching fractions and those of the subsequent $\beta$-scissions are indicated in Fig. 4. While these values are changing with temperature they are a good representation of the main reaction zone.

No attempt was made to separate the hydroxyalkyl and alkoxy radicals 1-6 because their ionization energies are likely to be very similar and the photoionization cross-sections are not known. Instead, a lumped mole fraction profile for all $\mathrm{C}_{5} \mathrm{H}_{11} \mathrm{O}$ radicals is shown in Figure $5 \mathrm{a}$ together with the model results for these species. Most of these species are predicted to be present only in very small concentrations, which are below the detection limit of the mass spectrometer (in the order of a few ppm). Noteworthy is the late appearance and intermediate like shape of the $\alpha$ radical in the model results. The sum of the predicted mole fractions for the $\mathrm{C}_{5} \mathrm{H}_{11} \mathrm{O}$ radicals is much larger than the experimentally determined mole fraction. When assessing the models predictive capabilities, it has to be noted that the mole fraction for the fuel-radical has an uncertainty of a factor of 4 because (a) it has contributions of several unknown cross-sections and (b) this signal is also heavily obstructed by both fragmentation from the fuel and ${ }^{13} \mathrm{C}$ isotopes of the $\mathrm{C}_{5}$ unsaturated alcohols and aldehyde which are abundant in significant amounts.

As for the dehydrogenation products, the aldehyde 7 is a major intermediate at $m / z=86$ (identified by its ionization energy of $9.59 \mathrm{eV}$ ), because it is very stable and can be produced both directly from 1 and 2 or via the 2-methylbut-1-en-1-ol 8 through a tautomerization reaction. Of all the $\mathrm{C}_{5} \mathrm{H}_{10} \mathrm{O}$ isomers, the model predicts the aldehyde 7 to peak closest to the burner and in the highest concentration (Fig. 5b). The peak of the mole fraction of the second highest concentrated dehydrogenation product (2-methylbut-3-en-1-ol) is already one order of magnitude lower than that and appears slightly later. The enols 8-11 were not resolved experimentally and are only shown as 
combined mole fraction profile in Figure $5 \mathrm{~b}$. Because of the stronger $\mathrm{C}-\mathrm{H}$ bond compared to a typical C-C bond, the model predicts less than $1 \%$ of each radical reacts to enols with $43 \%$ of 6 isomerizing to 1. It can be argued that the level of agreement between experimental and modeled aldehyde and enol mole fractions is still within the combined errors of experiment and simulation. At $\mathrm{m} / \mathrm{z}=72.0575$ the flame-sampled photoionization efficiency curve indicates that most likely all three $\mathrm{C}_{4} \mathrm{H}_{8} \mathrm{O}$ isomers are present. A weak onset can be observed at $8.4 \mathrm{eV}$ corresponding to but-1-en-1-ol 12 followed by a strong signal at $8.6 \mathrm{eV}$ corresponding to but-2-en-1-ol $\mathbf{1 5}$, and finally one at $9.3 \mathrm{eV}$ corresponding to 2-methylprop-2-en-1-ol 14. At m/z=70.08 mainly 2-methyl-1-butene (9.1 eV) 13 can be seen with a very minor contribution of 2-methyl-2-butene $(8.7 \mathrm{eV})$. Fig. 6 shows the mole fraction profiles of 13, 18, 19, and 21 each representing the decomposition of a different fuel-H radical compared to the model predictions. As can be seen the position and shape are represented excellently and the absolute values are within the experimental error for all those species. Therefore, we conclude that the calculated branching fractions of the fuel decomposition pathways represent the underlying combustion chemistry well.

The radicals at $m / z=57.070\left(\mathrm{C}_{4} \mathrm{H}_{9}\right)$ and $m / z=59.047\left(\mathrm{C}_{3} \mathrm{H}_{7} \mathrm{O}\right)$ representing the remaining fuel decomposition pathways not previously discussed, could not be quantified isomer-selective as species 17 and 16, respectively. Instead, we quantified the overall $\mathrm{C}_{4} \mathrm{H}_{9}$ and $\mathrm{C}_{3} \mathrm{H}_{7} \mathrm{O}$ contributions with estimated photoionization cross sections. To get a rough idea about the modeling predictions of those pathways, Fig. 7 shows the comparisons for formaldehyde and ethylene, even though these species are much less specific to the decomposition of fuel radicals. The ethylene profiles are in good agreement while the formaldehyde agreement is good in shape and position. The latter might indicate, in conjunction with the underprediction of 2-methylbutanal, that rate coefficients giving rise to the branching of radical 1 need some more investigation.

As can be seen in Figure 8a the concentration of the methyl radical is quite high with a peak mole fraction of $7 \times 10^{-3}$ in the experiment, which is likely to be caused by the fact that three direct decomposition products of the 2-methylbutanol form this intermediate. The high methyl concentration increases the probability of methylation reactions. For instance toluene and ethyl 
methyl ether are formed by combination of methyl with phenyl or methoxy, respectively, in amounts above the detection limit as shown in Fig. 8b. With regards to other aromatic species, Fig. 8b also shows the experimentally derived mole fraction profile of benzene. The present focus lies in the alcohol combustion chemistry model, which does not contain an aromatics sub-model, thus no model predictions are presented for benzene. Fig. 8c shows the experimental and modeled mole fraction profile of propargyl $\left(\mathrm{C}_{3} \mathrm{H}_{3}\right)$, which is an important benzene precursor. Methyl recombination can form ethane near the burner, as shown in Fig. 8d, with excellent agreement.

Furthermore, a number of species are now observable because of the high mass resolution. For instance $m / z=74$ shows neither $\mathrm{C}_{6} \mathrm{H}_{2}$ nor the butanol isomers $\mathrm{C}_{4} \mathrm{H}_{10} \mathrm{O}$, but $\mathrm{C}_{3} \mathrm{H}_{6} \mathrm{O}_{2}$ with an appearance energy of $9.8 \mathrm{eV}$ which would correspond to the unlikely dioxolanes. A stronger threshold at $10.05 \mathrm{eV}$ possibly indicates the presence of hydroxypropanone. This species is interesting because the shape of the profile closely follows the fuel profile. At $m / z=60.02\left(\mathrm{C}_{2} \mathrm{H}_{4} \mathrm{O}_{2}\right)$ the expected onset at $10.6 \mathrm{eV}$ corresponds to acetic acid, but an earlier onset at $9.65 \mathrm{eV}$ potentially corresponding to 1,2 ethendiol can be observed. Owing to the mass resolution, the $\mathrm{C}_{2} \mathrm{H}_{4} \mathrm{O}_{2}$ intermediates can be clearly separated from the likewise present $\mathrm{C}_{3} \mathrm{H}_{8} \mathrm{O}$ species. An ionization energy of $9.72 \mathrm{eV}$ suggests the presence of methylethylether on $\mathrm{m} / \mathrm{z}=60.06$. The much stronger onset at $10.2 \mathrm{eV}$ of the later composition shows the expected presence of propanol. Many of the newly detected species are not yet present in the combustion chemistry model. Their concentrations are in the order of $10^{-5}$ and further studies are needed to investigate their relevance.

\section{Conclusions}

This study probed the chemical structure of a laminar premixed low-pressure flame of 2methylbutanol using by flame-sampling molecular-beam mass spectrometry. The obtained mole fraction profiles were compared to the simulated profiles for the same conditions of an independently assembled model. The proposed model was able to well predict existing literature data for high 
temperature ignition delay and laminar burning velocity. The present premixed flame results show that based on a set of established rate rules, it is possible to assemble predictive models for new potential biofuels. The assumption that $\mathrm{H}$-abstraction reactions followed by $\beta$-scissions of the respective radicals are the major fuel decomposition pathways appears to be warranted. It can also be seen that, although of small importance for the overall flame structure, the aromatic chemistry cannot be neglected even under stoichiometric conditions. Fundamental experimental and theoretical studies on enol and aldehyde chemistry can improve model predictions of several intermediates. To assess and improve the capabilities of the model further, it should be extended to include low temperature chemistry and validated against further experiments in a broader parameter space.

\section{Acknowledgements}

The measurements were performed within the "Flame Team" collaboration at the Advanced Light Source and we thank the students and postdocs for the help with the data acquisition. The experiments have profited from the expert technical assistance of Paul Fugazzi. AL and NH are supported by the Energy Frontier Research Center for Combustion Science (Grant No. DESC0001198). SP and SMS acknowledge funding from the Clean Combustion Research Center (CCRC) at KAUST. The Advanced Light Source is supported by the Director, Office of Science, Basic Energy Sciences, US Department of Energy, under Contract No. DE-AC02-05CH11231. Sandia is a multi-program laboratory operated by Sandia Corporation, a Lockheed Martin Company, for the National Nuclear Security Administration under contract DE-AC04-94-AL85000. 


\section{References}

[1] C. Weber, A. Farwick, F. Benisch, D. Brat, H. Dietz, T. Subtil and E. Boles, Appl. Microbiol. Biotechnol. 87 (4) (2010) 1303-1315.

[2] P. P. Peralta-Yahya and J. D. Keasling, Biotechnol. J. 5 (2) (2010) 147-162.

[3] S. Lubieniechi, T. Peranantham and D. B. Levin, Recent Pat. DNA Gene Sequences 7 (1) (2013) 25-35.

[4] C. S. McEnally, L. D. Pfefferle, B. Atakan and K. Kohse-Höinghaus, Prog. Energy Combust. Sci. 32 (3) (2006) 247-294.

[5] A. F. Cann and J. C. Liao, Appl. Microbiol. Biotechnol. 81 (1) (2008) 89-98.

[6] C. R. Shen and J. C. Liao, Energy Environ. Sci. 5 (11) (2012) 9574-9583.

[7] J. H. Cai, W. H. Yuan, L. L. Ye, Z. J. Cheng, Y. Z. Wang, L. D. Zhang, F. Zhang, Y. Y. Li and F. Qi, Combust. Flame 160 (10) (2013) 1939-1957.

[8] P. Oßwald, H. Güldenberg, K. Kohse-Höinghaus, B. Yang, T. Yuan and F. Qi, Combust. Flame 158 (1) (2011) 2-15.

[9] M. Sarathy, P. Oßwald, N. Hansen and K. Kohse-Höinghaus, Prog. Energy Combust. Sci. submitted (2013).

[10] N. Hansen, M. R. Harper and W. H. Green, Phys. Chem. Chem. Phys. 13 (45) (2011) 2026220274.

[11] N. Hansen, S. S. Merchant, M. R. Harper and W. H. Green, Combust. Flame 160 (11) (2013) 2343-2351.

[12] K. Kohse-Höinghaus, P. Oßwald, T. A. Cool, T. Kasper, N. Hansen, F. Qi, C. K. Westbrook and P. R. Westmoreland, Angew. Chem., Int. Ed. 49 (21) (2010) 3572-3597.

[13] L. Zhao, L. L. Ye, F. Zhang and L. D. Zhang, J. Phys. Chem. A 116 (37) (2012) 9238-9244.

[14] Q. Q. Li, E. J. Hu, X. Y. Zhang, Y. Cheng and Z. H. Huang, Energy Fuels 27 (2) (2013) 11411150 .

[15] J. Campos-Fernandez, J. M. Arnal, J. Gomez, N. Lacalle and M. Pilar Dorado, Fuel 107 (2013) 866-872.

[16] A. Lucassen, J. Warkentin, N. Hansen, S. W. Park and M. Sarathy, Proceedings of the 8th U. S. National Combustion Meeting (2013).

[17] S. M. Sarathy, S. Park, B. W. Weber, W. Wang, P. S. Veloo, A. C. Davis, C. Togbe, C. K. Westbrook, O. Park, G. Dayma, Z. Luo, M. A. Oehlschlaeger, F. N. Egolfopoulos, T. Lu, W. J. Pitz, C.-J. Sung and P. Dagaut, Combust. Flame 160 (12) (2013) 2712-2728.

[18] O. Welz, J. D. Savee, A. J. Eskola, L. Sheps, D. L. Osborn and C. A. Taatjes, Proc. Combust. Inst. 34 (2013) 493-500. 
[19] Q. Q. Li, E. J. Hu, Y. Cheng and Z. H. Huang, Fuel 112 (2013) 263-271.

[20] C.-W. Zhou, S. J. Klippenstein, J. M. Simmie and H. J. Curran, Proc. Combust. Inst. 34 (2013) 501-509.

[21] S. S. Vasu and S. M. Sarathy, Energy Fuels 27 (11) (2013) 7072-7080.

[22] E. R. Ritter and J. W. Bozzelli, Int. J. Chem. Kinet. 23 (9) (1991) 767-778.

[23] L. S. Tee, S. Gotoh and W. E. Stewart, Ind. Eng. Chem. Fund. 5 (3) (1966) 356-\&.

[24] C. Tang, L. Wei, X. Man, J. Zhang, Z. Huang and C. K. Law, Combust. Flame 160 (3) (2013) 520-529.

[25] CHEMKIN-PRO, Reaction Design: San Diego (2009).

[26] A. Lucassen, N. Labbe, P. R. Westmoreland and K. Kohse-Höinghaus, Combust. Flame 158 (9) (2011) 1647-1666.

[27] T. A. Cool, A. McIlroy, F. Qi, P. R. Westmoreland, L. Poisson, D. S. Peterka and M. Ahmed, Rev. Sci. Instrum. 76 (9) (2005).

[28] J. Coles and M. Guilhaus, TrAC, Trends Anal. Chem. 12 (5) (1993) 203-213.

[29] P. Osswald, U. Struckmeier, T. Kasper, K. Kohse-Höinghaus, J. Wang, T. A. Cool, N. Hansen and P. R. Westmoreland, J. Phys. Chem. A 111 (19) (2007) 4093-4101.

[30] T. Kasper, A. Lucassen, A. W. Jasper, W. Li, P. R. Westmoreland, K. Kohse-Höinghaus, B. Yang, J. Wang, T. A. Cool and N. Hansen, Z. Phys. Chem. 225 (11-12) (2011) 1237-1270.

[31] S. M. Sarathy, S. Vranckx, K. Yasunaga, M. Mehl, P. Oßwald, W. K. Metcalfe, C. K. Westbrook, W. J. Pitz, K. Kohse-Höinghaus, R. X. Fernandes and H. J. Curran, Combust. Flame 159 (6) (2012) 2028-2055. 
Figures:

Fig. 1

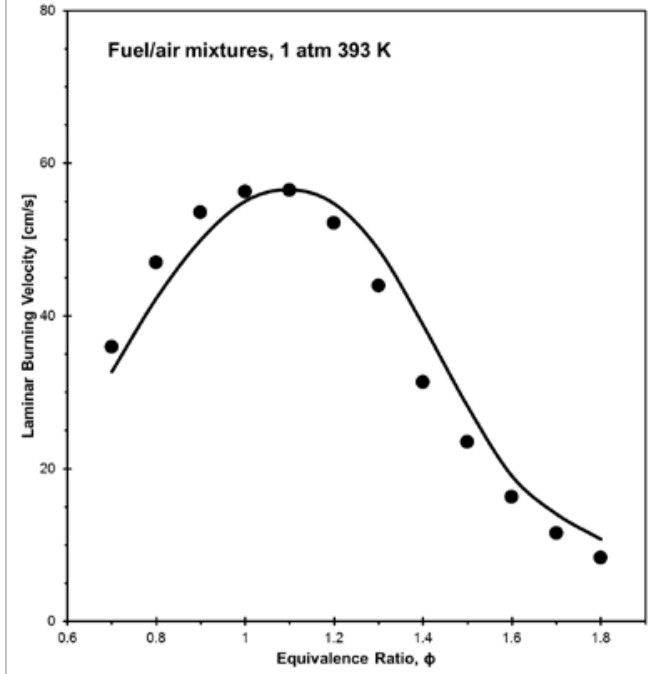

Figure 1: Predicted (line) and experimental (symbols) laminar burning velocity for 2-methylbutanol.

Experimental data are from Ref. [19]. 
Fig. 2
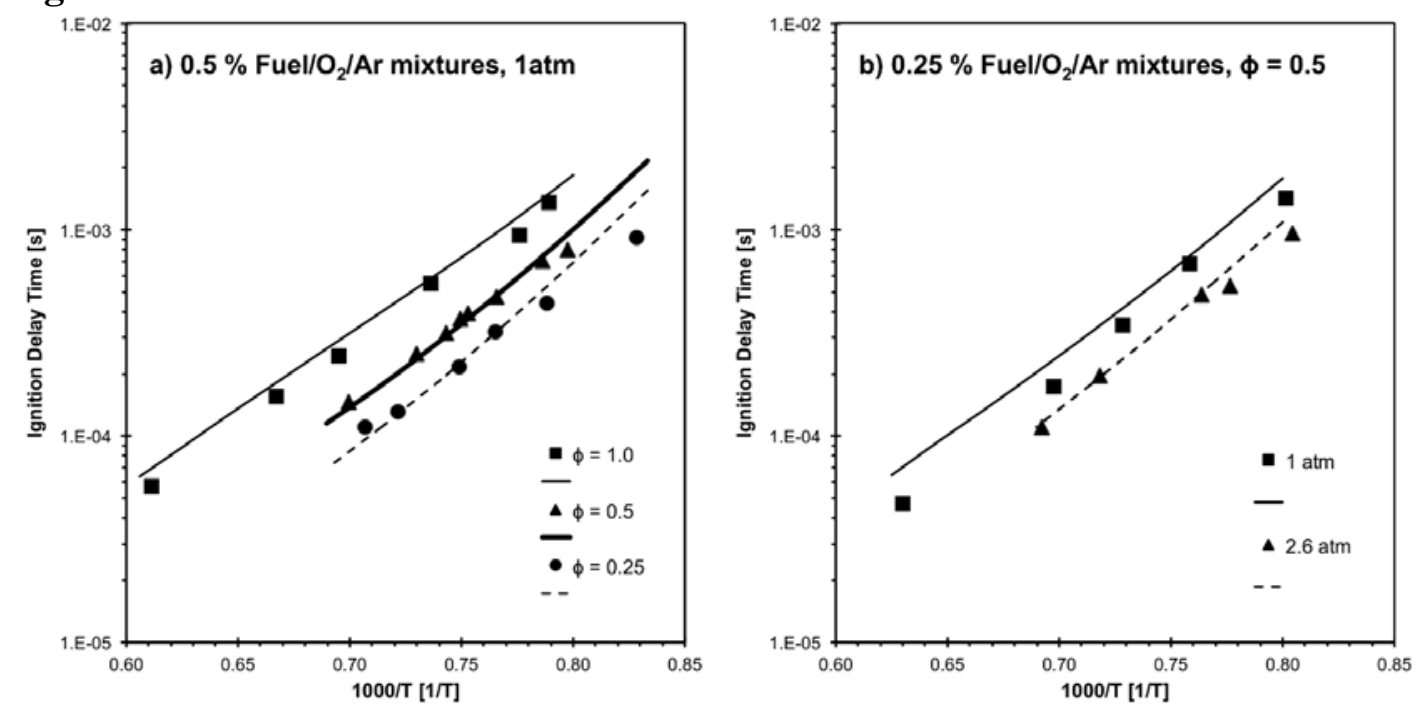

Figure 2: Predicted (line) and experimental (symbols) ignition delay times for 2-methylbutanol. Experimental data are from Ref.[24]. 
Fig. 3

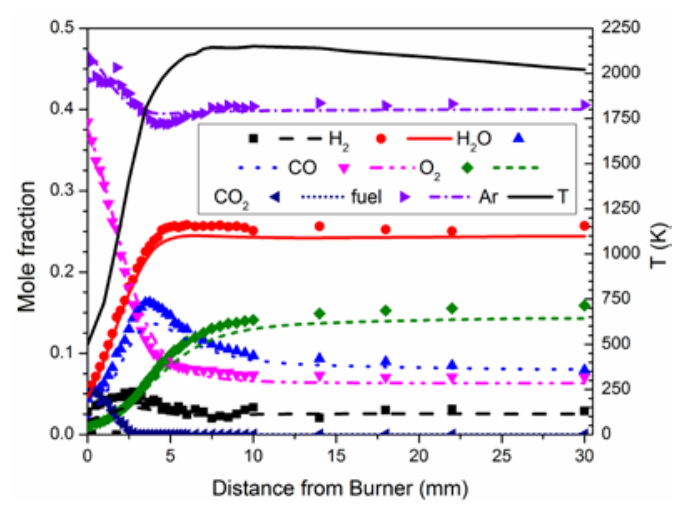

Figure 3: Comparison of experimental (symbols) and simulated (lines) mole fractions for the main species. The temperature profile is shown on the right axis. 
Fig. 4

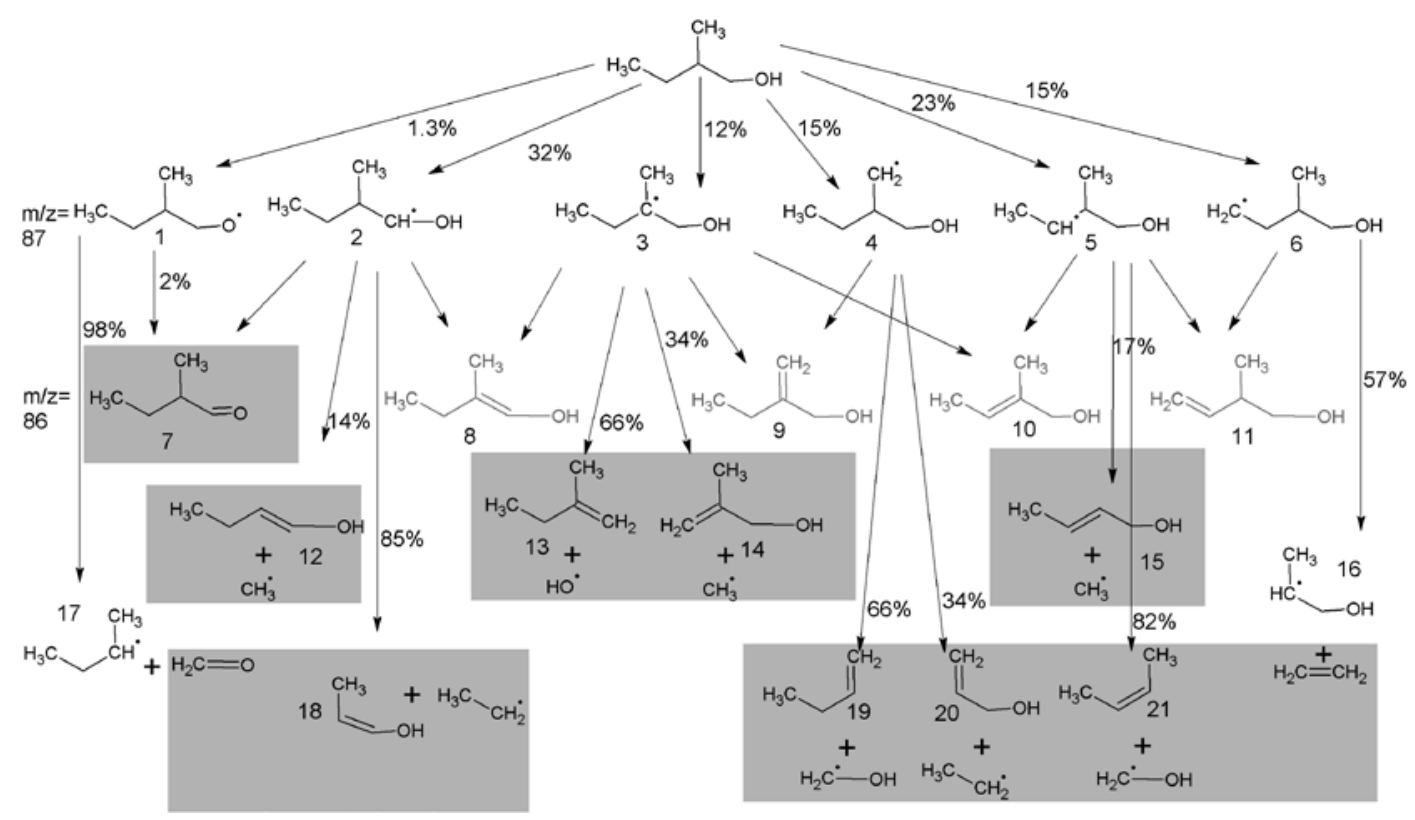

Figure 4: Consumption reactions of 2-methylbutanol and their predicted significances at $2.0 \mathrm{~mm}$ above the burner surface. Highlighted species could be identified unambiguously. 
Fig. 5
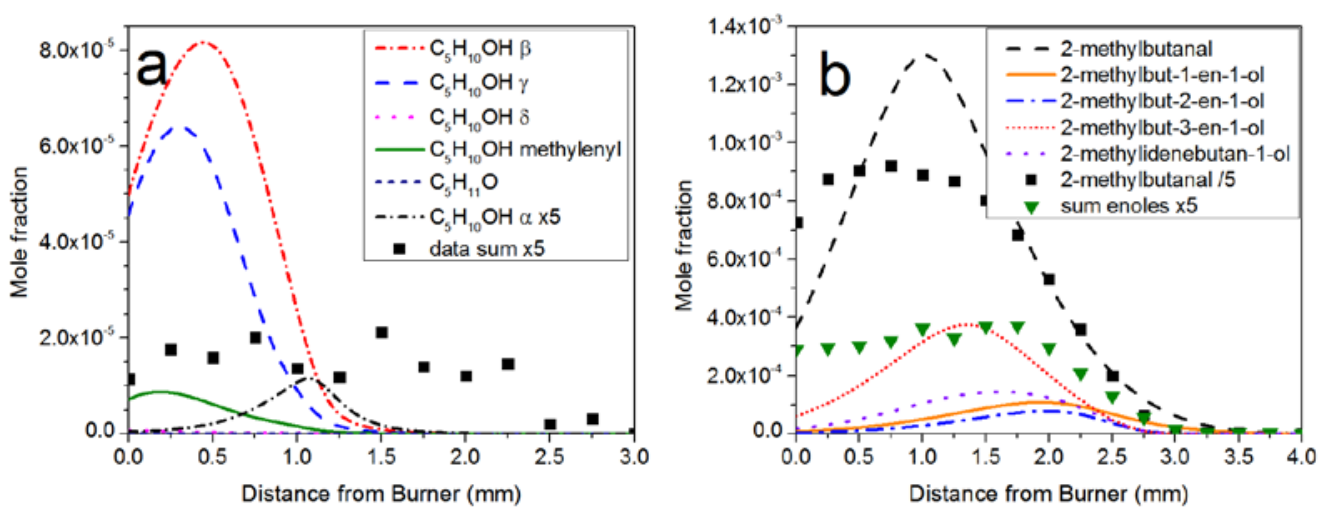

Figure 5. Simulated mole fractions of the fuel-H and fuel-2H intermediates compared to lumped experimental species. For better visualization, the modeled profile for $\mathrm{C}_{5} \mathrm{H}_{10} \mathrm{OH}$ and the experimental profiles for $\mathrm{C}_{5} \mathrm{H}_{11} \mathrm{O}$ and $\mathrm{C}_{5}$-enols have been multiplied by a factor of five. The experimental profile for 2-methylbutanal has been divided by a factor of five. 
Fig. 6
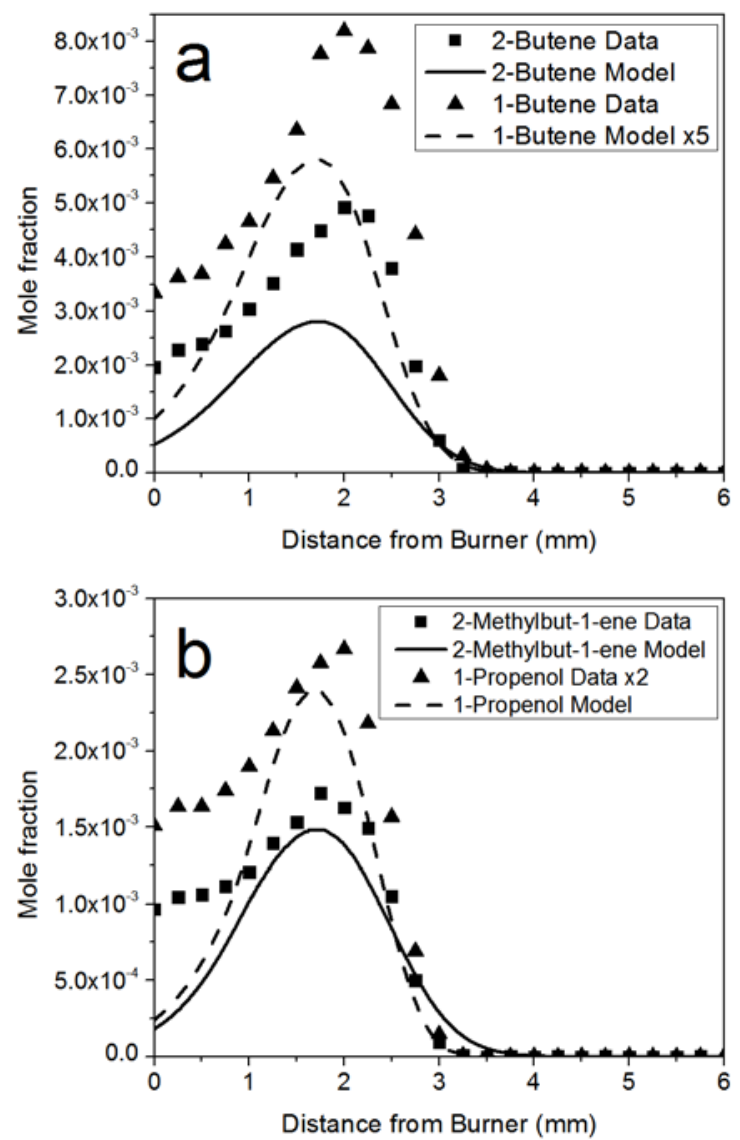

Figure 6. Comparison of experimental (symbols) and modeled (lines) mole fraction profiles for consumption pathway specific intermediates. For better visualization, the modeled result for 1butene is multiplied by a factor of five and the experimental profile for prop-1-enol is multiplied by a factor of two. 
Fig. 7
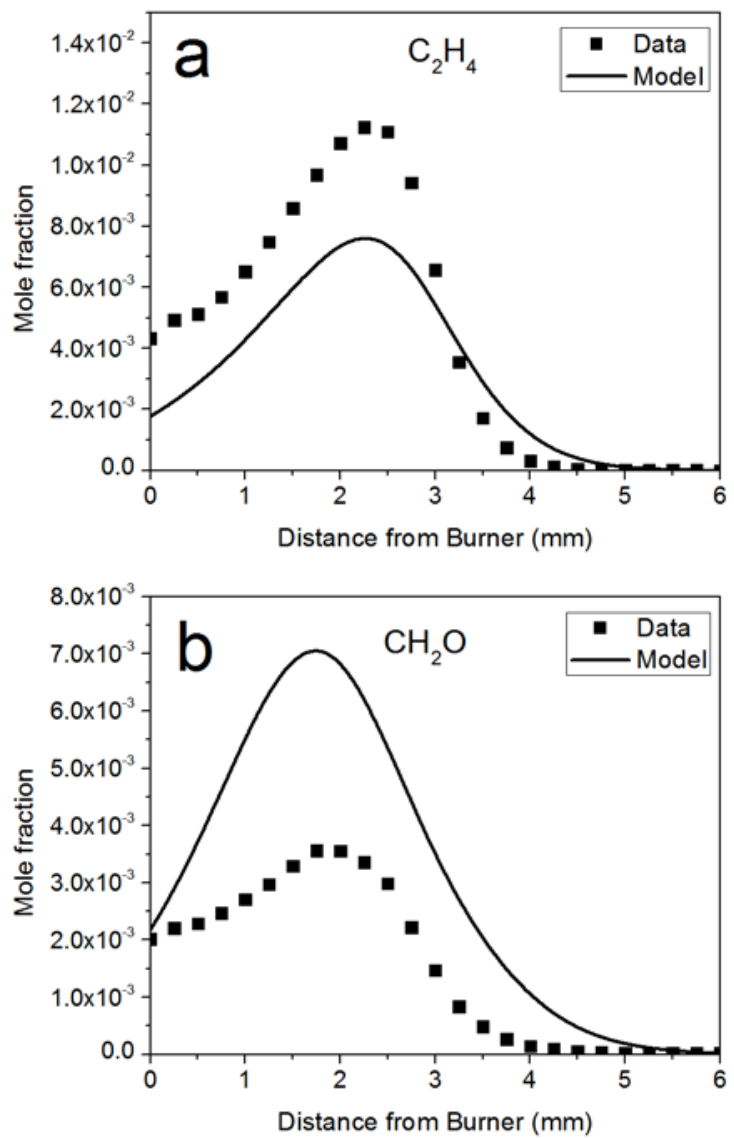

Figure 7. Experimental (symbols) and modeled (lines) mole fraction profiles of (a) $\mathrm{C}_{2} \mathrm{H}_{4}$ and (b) formaldehyde $\left(\mathrm{CH}_{2} \mathrm{O}\right)$ 
Fig. 8
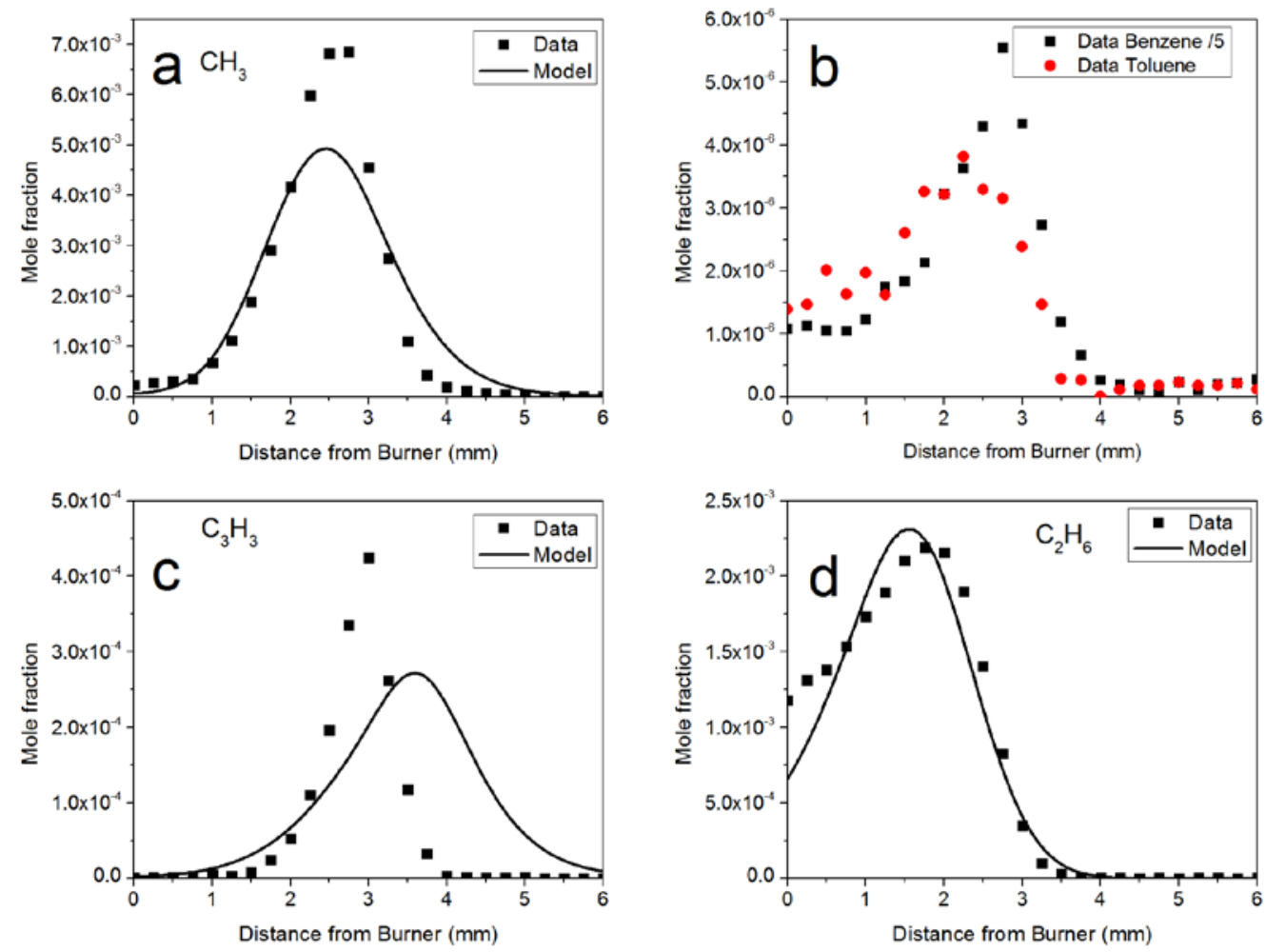

Figure 8. Experimental (symbols) and modeled (lines) mole fraction profiles of (a) $\mathrm{CH}_{3}$, (b) $\mathrm{C}_{6} \mathrm{H}_{6}$ (benzene) and $\mathrm{C}_{7} \mathrm{H}_{8}$ (toluene), (c) $\mathrm{C}_{3} \mathrm{H}_{3}$, and (d) $\mathrm{C}_{2} \mathrm{H}_{6}$ 


\section{List of Figure Captions}

Figure 1:

Predicted (line) and experimental (symbols) laminar burning velocity for 2-methylbutanol. Experimental data are from Ref. [19].

\section{Figure 2:}

Predicted (line) and experimental (symbols) ignition delay times for 2-methylbutanol. Experimental data are from Ref.[24].

\section{Figure 3:}

Comparison of experimental (symbols) and simulated (lines) mole fractions for the main species. The temperature profile is shown on right axis.

\section{Figure 4:}

Consumption reactions of 2-methylbutanol and their predicted significances at $2.0 \mathrm{~mm}$ above the burner surface. Highlighted species could be identified unambiguously.

\section{Figure 5:}

Simulated mole fractions of the fuel- $\mathrm{H}$ and fuel-2H intermediates compared to lumped experimental species. For better visualization, the modeled profile for $\mathrm{C}_{5} \mathrm{H}_{10} \mathrm{OH}$ and the experimental profiles for $\mathrm{C}_{5} \mathrm{H}_{11} \mathrm{O}$ and $\mathrm{C}_{5}$ enols have been multiplied by a factor of five. The experimental profile for 2methylbutanal has been divided by a factor of five.

\section{Figure 6:}

Comparison of experimental (symbols) and modeled (lines) mole fraction profiles for consumption pathway specific intermediates. For better visualization, the modeled result for 1-butene is multiplied by a factor of five and the experimental profile for prop-1-enol is multiplied by a factor of two. 
Figure 7. Experimental (symbols) and modeled (lines) mole fraction profiles of (a) $\mathrm{C}_{2} \mathrm{H}_{4}$ and (b) formaldehyde $\left(\mathrm{CH}_{2} \mathrm{O}\right)$

Figure 8. Experimental (symbols) and modeled (lines) mole fraction profiles of (a) $\mathrm{CH}_{3}$, (b) $\mathrm{C}_{6} \mathrm{H}_{6}$ (benzene) and $\mathrm{C}_{7} \mathrm{H}_{8}$ (toluene), (c) $\mathrm{C}_{3} \mathrm{H}_{3}$, and (d) $\mathrm{C}_{2} \mathrm{H}_{6}$ 
Supplemental Material

1. Experimental molefractions

2. Full kinetic mechanism (2methylbutanol_high_v1.2.inp)

3. Transport Data (File 2methylbutanol_tran.dat)

4. Thermodynamic data (File 2 methylbutanol_therm.dat) 